\title{
Cancer Risk of Inhalation Exposure to Cd, Cr, As, Be and Ni in Ambient Air
}

\author{
Heba M. Adly ${ }^{1}$, Saleh A. K. Saleh ${ }^{1,2}$, Abdullah A. Saati ${ }^{3}$, Sameer H. Fatani ${ }^{1}$ \\ ${ }^{1}$ Biochemistry Department, Faculty of Medicine, Umm Al-Qura University, Makkah, KSA \\ ${ }^{2}$ Oncology Diagnostic Unit, Faculty of Medicine, Ain Shams University, Cairo, Egypt \\ ${ }^{3}$ Community Medicine Department, Faculty of Medicine, Umm Al-Qura University, Makkah, KSA \\ Email: Saleh-A-S@hotmail.com
}

How to cite this paper: Adly, H.M., Saleh, S.A.K., Saati, A.A. and Fatani, S.H. (2017) Cancer Risk of Inhalation Exposure to Cd, $\mathrm{Cr}, \mathrm{As}, \mathrm{Be}$ and $\mathrm{Ni}$ in Ambient Air. Journal of Environmental Protection, 8, 290-300. https://doi.org/10.4236/jep.2017.83022

Received: February 4, 2017

Accepted: March 20, 2017

Published: March 23, 2017

Copyright $(9) 2017$ by authors and Scientific Research Publishing Inc. This work is licensed under the Creative Commons Attribution International License (CC BY 4.0).

http://creativecommons.org/licenses/by/4.0/

\begin{abstract}
Particulate matter may comprise toxic trace elements with carcinogenic effects. Of these trace elements, Cadmium (Cd), Chromium (Cr), Arsenic (As), Beryllium $(\mathrm{Be})$ and Nickel $(\mathrm{Ni})$ are classified as probable human carcinogens. During the annual Hajj pilgrimage, 2.3 million pilgrims stay in Makkah, Saudi Arabia; the increased vehicle traffic contributes to elevated concentrations of particulate matter. We aimed to determine the excess cancer risk (ECR) associated with inhalation exposure in the Makkah population. This study was conducted in the Arafat area, which is a highly-crowded area during Hajj. Inductively coupled plasma-mass spectrometry (ICP-MS) was used for trace element analysis. ECR resulting from inhalation exposure to each metal was calculated in accordance with the unit risk suggested by the Integrated Risk Information System. In summer, including Hajj, mean $\mathrm{Cd}, \mathrm{Cr}, \mathrm{As}, \mathrm{Be}$, and $\mathrm{Ni}$ atmospheric concentrations were $0.098,0.008,0.26,0.03$, and $0.012 \mu \mathrm{g} / \mathrm{m}^{3}$, respectively; in autumn, values were $0.06,0.006,0.16,0.002$, and $0.01 \mu \mathrm{g} / \mathrm{m}^{3}$, respectively. ECRs were $1.08 \times 10^{-4}, 7.21 \times 10^{-4}, 4.0 \times 10^{-6}, 4.6 \times 10^{-6}$, and $2.4 \times 10^{-6}$, respectively, exceeding the acceptable inhalation risk level $\left(1.0 \times 10^{-6}\right)$ set by the US Environmental Protection Agency for each element. Higher atmospheric trace element concentrations in summer were due to high temperatures that increased atmospheric turbulence, leading to a greater amount of re-suspended dust from roads and blowing sand particles. These findings can be used by relevant authorities while developing regulations and strategies for developing air quality management to improve the health of pilgrims; however, larger prospective studies are required to estimate ECR in different seasons.
\end{abstract}

\section{Keywords}

Carcinogens, Trace Elements, Particulate Matter, $\mathrm{PM}_{10}$ 


\section{Introduction}

Since the metals can exist in a particle form, they can contribute to particulate matter (PM) levels or react with gases in the atmosphere to form pollutant compounds [1]. Atmospheric PM is more complex than other air contaminants because of its chemical composition and physical properties, including density, concentration, and size distribution [2]. PM may consist of several toxic trace heavy metals that are potentially harmful to human health because of their carcinogenic properties [3] [4] [5] [6] [7].

The United States Environmental Protection Agency (USEPA) considered Cd as a potential human carcinogen and had classified it as a group B1 carcinogen. The inhalation risk unit (the estimated increased cancer risk from inhalation exposure to a concentration of $1 \mu \mathrm{g} / \mathrm{m}^{3}$ over an individual's lifetime) of Cd has been calculated as $1.8 \times 10^{-3}\left(\mu \mathrm{g} / \mathrm{m}^{3}\right)$. USEPA estimated that, if a person were to continuously breathe air containing $\mathrm{Cd}$ at a concentration of $0.0006 \mu \mathrm{g} / \mathrm{m}^{3}\left(6 \times 10^{-7} \mathrm{mg} / \mathrm{m}^{3}\right)$ throughout his or her lifetime, he or she would theoretically have less than one in a million risk of cancer development due to $\mathrm{Cd}$ inhalation. In contrast, those continuously breathing air containing $0.06 \mu \mathrm{g} / \mathrm{m}^{3}\left(6 \times 10^{-5} \mathrm{mg} / \mathrm{m}^{3}\right) \mathrm{Cd}$ would have an approximately one in 10,000 risk of cancer development due to $\mathrm{Cd}$ inhalation [8].

Chromium is classified as a Group A carcinogen. A previous occupational study of chromate production workers reported that continuously breathing Cr-contaminated air was associated with an inhalation risk unit for $\mathrm{Cr}$ of $1.2 \times 10^{-2}$ $\left(\mu \mathrm{g} / \mathrm{m}^{3}\right)^{-1}$. In addition, those who continuously breathe $\mathrm{Cr}$-contaminated air $\left(0.00008 \mu \mathrm{g} / \mathrm{m}^{3}\left[8 \times 10^{-8} \mathrm{mg} / \mathrm{m}^{3}\right]\right)$ throughout their lives may have less than one in a million risk of cancer [8] due to $\mathrm{Cr}$ inhalation. Arsenic is also classified as a group A carcinogen. Studies have reported a strong association between As inhalation and lung cancer risk. Moreover, studies have reported a strong association between As ingestion or exposure and elevated risk of bladder, liver, lung, and skin cancers [9] [10]. Beryllium is a group B1 carcinogen. Studies have reported a causal relationship between Be exposure and lung cancer [11] [12]. Nickel dust and $\mathrm{Ni}$ bisulfide are categorized by the USEPA as group A carcinogens. Ni carbonate, Ni carbonyl, Ni hydroxide, and Ni sulfate are classified by the US National Occupational Health and Safety Commission as category 3 carcinogens and Ni oxide and $\mathrm{Ni}$ bisulfide as category 1 carcinogens. In addition, $\mathrm{Ni}$ carbonyl is classified as a category 2 carcinogen [13].

Some previous studies indicated that $\mathrm{PM}_{10}$ levels in Makkah, Saudi Arabia exceeded the national and international standards set for the protection of human health [14] and suggested a detailed investigation of the effects of $\mathrm{PM}_{10}$ and $\mathrm{PM}_{2.5}$ exposure on human health using data from multiple locations [15] [16]. Another study revealed high levels of $\mathrm{PM}_{10}$ in different location in Makkah (Al Haram) [17]. Moreover, previous study in Makkah showed significantly positive trends in $\mathrm{PM}_{10}$ concentrations; several reasons for the high particulate concentrations in Makkah were suggested, including an increasing number of diesel vehicles, especially during the Hajj season for transportation of pilgrims, increasing construc- 
tion activities in Makkah, changing weather patterns, and increasing proportion of windblown and re-suspended dust particles [18].

Hence, the present study aimed to determine the ECR associated with inhalation exposure to five heavy metals ( $\mathrm{Cd}, \mathrm{Cr}, \mathrm{As}, \mathrm{Be}$, and $\mathrm{Ni}$ ) in ambient air. Since the carcinogenicity risk for trace elements in Makkah is unknown, ECR from inhalation exposure to each metal was calculated. To our knowledge, no modeling studies have been published concerning air pollution in Makkah and its expected effect on population health, especially regarding cancer risk. Thus, this is the first study to examine cancer risk with respect to exposure to trace elements in Makkah.

\section{Materials and Methods}

\subsection{Sampling Location}

This study was conducted in the Arafat area $\left(21.35\right.$ [21 $\left.21^{\prime} 1 " \mathrm{~N}\right]$ latitude; 39.97 [ $39^{\circ} 58^{\prime} 1$ "E] longitude) east of Makkah, Figure 1. The Arafat area was selected as it represents a highly-crowded area during the Hajj season, Table 1 and Table 2 [19].

\subsection{Meteorological Measurements}

On-site measurement of air temperature, wind speed, wind direction, ultraviolet (UV) radiation, and rainfall rate was performed using the Davis Instruments 6163 Vantage Pro2 Plus (Davis Instruments, USA). Meteorological data were recorded at a height of $10 \mathrm{~m}$ on a $47-\mathrm{mm}$ Teflon filter at $16.6 \mathrm{l} / \mathrm{min}$ flow rate for 24 hours once a week for 6 months during the summer and autumn in 2014, in accordance with the USEPA standard method (Method 29 as updated in 2000). Weather information was collected, including data regarding temperature, humidity, rainfall amount, wind speed, wind direction, wind chill factor, and barometric pressure. $\mathrm{UV}$ radiation was determined by measuring the irradiance at UV wavelength, as

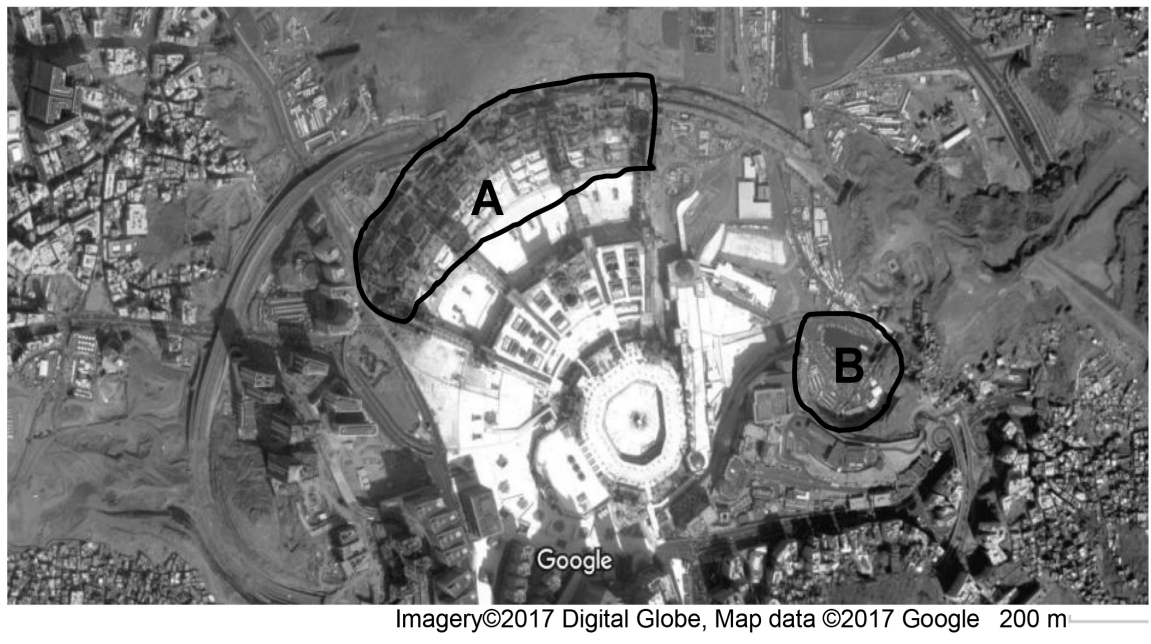

Figure 1. Map of the Makkah area showing various sources of emissions. (A) shows the construction and development area of Masjid Al-Haram; (B), Main bus station stand along Masjid Al-Haram. 
Table 1. Number of pilgrims from 1995-2012 [19].

\begin{tabular}{|c|c|c|c|}
\hline \multicolumn{4}{|c|}{ The number of pilgrims for the years from $1416 \mathrm{H}(1995 \mathrm{G})$ to $1433 \mathrm{H}(2012 \mathrm{G})$} \\
\hline Year $(H / G)$ & Pilgrims from Outside Saudi Arabia & Pilgrims from Saudi Arabia & Total \\
\hline $1416 / 1995$ & $1,080,465$ & 784,769 & $1,865,234$ \\
\hline $1417 / 1996$ & $1,168,591$ & 774,260 & $1,942,851$ \\
\hline $1418 / 1997$ & $1,132,344$ & 699,770 & $1,832,114$ \\
\hline $1419 / 1998$ & $1,056,730$ & 775,268 & $1,831,998$ \\
\hline $1420 / 1999$ & $1,267,555$ & 571,599 & $1,839,154$ \\
\hline $1421 / 2000$ & $1,363,992$ & 549,271 & $1,913,263$ \\
\hline $1422 / 2001$ & $1,354,184$ & 590,576 & $1,944,760$ \\
\hline $1423 / 2002$ & $1,431,012$ & 610,117 & $2,041,129$ \\
\hline $1424 / 2003$ & $1,419,706$ & 592,368 & $2,012,074$ \\
\hline $1425 / 2004$ & $1,534,769$ & 629,710 & $2,164,479$ \\
\hline $1426 / 2005$ & $1,557,447$ & 700,603 & $2,258,050$ \\
\hline $1427 / 2006$ & $1,654,407$ & 724,229 & $2,378,636$ \\
\hline $1428 / 2007$ & $1,707,814$ & 746,511 & $2,454,325$ \\
\hline $1429 / 2008$ & $1,729,841$ & 679,008 & $2,408,849$ \\
\hline $1430 / 2009$ & $1,613,965$ & 699,313 & $2,313,278$ \\
\hline $1431 / 2010$ & $1,799,601$ & 989,798 & $2,789,399$ \\
\hline $1432 / 2011$ & $1,828,195$ & $1,099,522$ & $2,927,717$ \\
\hline $1433 / 2012$ & $1,752,933$ & $1,408,641$ & $3,161,573$ \\
\hline
\end{tabular}

H, Hijri calendar; G, Gregorian calendar.

Table 2. Number of vehicles carrying pilgrims in Makkah, per car type [19].

\begin{tabular}{ccccc}
\hline \multirow{2}{*}{ Vehicle Type } & \multicolumn{2}{c}{ Numbers of Vehicles } & Difference & Percentage (\%) \\
\cline { 2 - 3 } Small & $1432 \mathrm{H} / 2011 \mathrm{G}$ & $1433 \mathrm{H} / 2012 \mathrm{G}$ & & 91 \\
Salon & 39,846 & 43,482 & +3636 & 80 \\
Pick-up truck & 16,277 & 17,580 & +1303 & 247 \\
Jeep & 4595 & 5732 & +1137 & 57 \\
Small bus & 8842 & 9342 & +500 & 22 \\
Big small & 5947 & 6077 & +130 & 461 \\
Trucks & 8325 & 12,166 & +3841 & 584 \\
Others & 231 & 366 & +135 & -44 \\
Total & 4915 & 4699 & -216 & 118 \\
\hline
\end{tabular}

H, Hijri calendar; G, Gregorian calendar.

the value significantly varies in ozone and cloud cover. Data (1-min averages) were automatically stored in a data log every $15 \mathrm{~min}$ for 1 year; daily averages were calculated. All data were sent directly to the laboratory via a modem. In all cases, data were collected in strict compliance with standards regarding meteorological monitoring equipment [20]. 


\section{3. $\mathrm{PM}_{10}$ Sampling and Analysis}

24 air samples were collected during summer, including the Hajj pilgrimage, and autumn using a mini volume sampler (Airmetrics, USA) at a height of $10 \mathrm{~m}$ on a 47 -mm Teflon filter at 16.6 1/min flow rate for 24 hours once a week for 6 months, in accordance with the USEPA standard method (Method 29/2000). PM samples were collected at a height of $10 \mathrm{~m}$ in the Arafat area on a filter of mixed cellulose ester membrane with a diameter of $47 \mathrm{~mm}$ (Whatman, Grade 1 Qualitative Filter Paper Standard Grade, USA). Each filter with the collected particles was placed and stored flat on a clean Petri dish during and after conditioning for weighing and storage. Filters were weighed pre- and post-sampling using an electronic microbalance (CITIZEN Micro Balance Model CM21P, USA). The filters were conditioned in a dry-keeper before and after collection. Teflon filters for $\mathrm{PM}_{10}$ were weighed and conditioned at a temperature of $35^{\circ} \mathrm{C}-40^{\circ} \mathrm{C}$ and humidity of $60 \%-70 \% \pm 5 \%$.

Sample filters were collected weekly for individual analysis. Particles collected on each filter were extracted with $7 \mathrm{ml}$ of nitric acid and $2 \mathrm{ml}$ of ultra-pure water (ASTM type 1 water from Millipore filtration system, Millipore Cooperation, Massachusetts, USA) followed by microwave-assisted acid digestion using $5 \mathrm{ml}$ of concentrated nitric acid, $3.0 \mathrm{ml}$ of concentrated hydrofluoric acid, $2.0 \mathrm{ml}$ of concentrated hydrochloric acid, and $1.0 \mathrm{ml}$ of hydrogen peroxide in each sample vessel. The sample vessels were sealed and placed in a rotor $(8 \times 100)$ for microwaving. Samples were analyzed for $\mathrm{Cd}, \mathrm{Cr}, \mathrm{As}, \mathrm{Be}$, and $\mathrm{Ni}$ concentrations in triplicate using inductively coupled plasma-mass spectrometry with a Perkin Elmer 7300 (Perkin Elmer, USA) per the manufacturer's instructions. Trace elements were detected using the appropriate wavelengths as per USEPA Method 200.7, and two factors were considered: The freedom from spectral interferences and the different sensitivities against the expected sample concentration. The observed interferences were compensated for by modifying the processing parameters, which was accomplished by adjusting the background correction points Table 3 .

\subsection{Quality Assurance and Quality Control Procedures}

Quality assurance and control (QA/QC) were performed for each sample by analyzing a control sample regularly with the samples to ensure reliability; reproducibility and linearity were determined for each analysis. A linear calibration curve was constructed using a blank and a five-point calibration curve using the following concentrations: $0.01,0.1,0.2,0.5$, and $1.0 \mathrm{ppm}$ for each of the five elements

Table 3. Instrumental and data acquisition parameters of the ICP-Perkin Elmer 7300.

\begin{tabular}{cccc}
\hline \multicolumn{2}{c}{ Instrumental parameters } & \multicolumn{2}{c}{ Data acquisition } \\
\hline RF power & $1400 \mathrm{~W}$ & Measuring mode & Segmented scan \\
Argon gas flow & $13-16 \mathrm{l} / \mathrm{min}$ & Point per peak & 5 \\
Nebulizer & $1.01 / \mathrm{min}$ & Scans/replicates & 6 \\
Plasma & $18.01 / \mathrm{min}$ & Replicate/sample & 6 \\
Sample uptake rate & $190 \mathrm{~s}$ & Integration time & $398.6 \mathrm{~s}$ \\
\hline
\end{tabular}


standards. All QC samples and samples containing elements with measured concentrations were within the range of the calibration curve. All calibration samples, QC samples, and production samples were analyzed using $2 \%$ nitric acid. In all 0.001-ppm QC checks, the determined concentration was within $20 \%$ of the true value, and the relative standard deviation was less than $6 \%$.

\subsection{Determination of ECR}

ECR was measured in accordance with the unit risk suggested by the Integrated Risk Information System based on the inhalation exposure to each metal for the five heavy metals in ambient air [21]. ECR for each metal was determined using the following mathematical formula: $\mathrm{ECR}=\mathrm{C}$ pollutant $\times$ IUR, where $\mathrm{C}$ pollutant refers to the mean concentration of heavy metal $(\mu \mathrm{g})$ and IUR refers to the inhalation unit risk for each metal, as determined using risk assessment data from the USEPA. The IUR for a human group B1 carcinogen is defined by the USEPA as the estimated upper limit of lifetime ECR resulting from continuous exposure to an agent at a concentration of $1 \mu \mathrm{g} / \mathrm{m}^{3}$ in ambient air. Therefore, the IUR is the greatest level of ECR for either mesothelioma or lung cancer from chronic inhalation exposure in the general US population. IURs are based on data obtained from epidemiologic studies on humans. The approach to determine the IUR from human epidemiologic data involves the quantitative evaluation of the exposure-response relationship (slope) for each element in the studied population [22].

The monthly mean concentration of trace elements was grouped for temporal comparisons to determine whether there was a statistical difference in the mean values per season. The two seasons included in the study were autumn (September through November) and summer (June through August). To test the null hypothesis that there would be a difference in the mean concentration of trace elements according to season, one-way ANOVA (SPSS, 2007) was performed with a significance level of $\alpha=0.05$.

\section{Results and Discussion}

Table 4 shows the descriptive statistical analysis of $\mathrm{PM}_{10}$ concentrations in the Arafat area in Makkah during the summer and autumn seasons. The average mass concentration of $\mathrm{PM}_{10}$ was 1.5 times higher in summer. This higher particulate concentration in summer may be attributed to re-suspension of dust from

Table 4. Twenty-four-hour average particulate matter $\left(\mathrm{PM}_{10}\right)$ concentrations $\left(\mu \mathrm{g} / \mathrm{m}^{3}\right)$ in the Arafat area from June to November 2014.

\begin{tabular}{ccccc}
\hline Months & Mean & SD & Min & Max \\
\hline June & 240.1 & 33.8 & 100.7 & 498.7 \\
July & 223.4 & 45.3 & 122.7 & 830.3 \\
August & 167.8 & 56.9 & 108.8 & 263.7 \\
September & 168.7 & 39.4 & 121.5 & 308.8 \\
October & 190.6 & 30.7 & 96.7 & 330.2 \\
November & 171.7 & 37.7 & 102.9 & 218.6 \\
\hline
\end{tabular}

$\mathrm{SD}$, Standard deviation. 
roads, natural dust storms, and automobile traffic. $\mathrm{PM}_{10}$ concentrations in the Arafat area increased during the pilgrimage period in summer owing to the high increase in pollution problems due to transportation, ultimately resulting in an unspecified amount of trace elements causing air pollution. Mean concentrations of airborne trace elements were significant per season.

A previous study, conducted in Makkah, reported that the annual average $\mathrm{PM}_{10}$ level was $233.38 \mu \mathrm{g} / \mathrm{m}^{3}$ [18], whereas a 2012 study in Jeddah showed an annual average $\mathrm{PM}_{10}$ concentration of $87.3 \mu \mathrm{g} / \mathrm{m}^{3}$ [13]; this is expected as Jeddah and Makkah have different pollution sources and atmospheric conditions. The weekly average $\mathrm{PM}_{10}$ concentration was highest on weekdays and lower on weekends [15]. In the present study, the highest monthly $\mathrm{PM}_{10}$ concentrations were observed in June and July (summer including Hajj); the corresponding concentrations were 240.1 and $223.4 \mu \mathrm{g} / \mathrm{m}^{3}$, respectively, which was significantly correlated with seasonal variation and the increased transportation and traffic activities during Hajj $(P<0.05)$; this has also been reported for the summer season by other studies which did not include Hajj [22]. The present study showed that a high PM concentration is strongly associated with the nature of the region, including temperature, wind speed and direction, humidity, and number of vehicles.

Regarding the trace element concentrations, the mean atmospheric concentrations of Cd, Cr, As, Be, and Ni were 0.098, 0.008, 0.26, 0.03, and $0.012 \mu \mathrm{g} / \mathrm{m}^{3}$, respectively, in summer, while the corresponding values in autumn were $0.06,0.006$, $0.16,0.002$, and $0.01 \mu \mathrm{g} / \mathrm{m}^{3}$, respectively, Figure 2. Among the samples of $\mathrm{PM}_{10}$ in the Arafat area, As concentration was the highest in all studied months in different seasons, Figure 3; this is strongly aligned with the results of another study conducted in Makkah that reported that $\mathrm{As}, \mathrm{Hg}$, and $\mathrm{Al}$ had the highest concentrations in different samples of $\mathrm{PM}_{10}$, total suspended particles, and $\mathrm{PM}_{2.5}$ [23]. The higher heavy metal concentration in summer is likely due to high temperature inversion, during which an increased number of $\mathrm{PM}_{10}$ particles are found closer to the surface owing to increased atmospheric turbulence and blowing dust, thus metal contaminants were transported and dispersed in the surrounding areas. The high concentration of As, a group A carcinogen, may cause a serious health threat to the Makkah population.

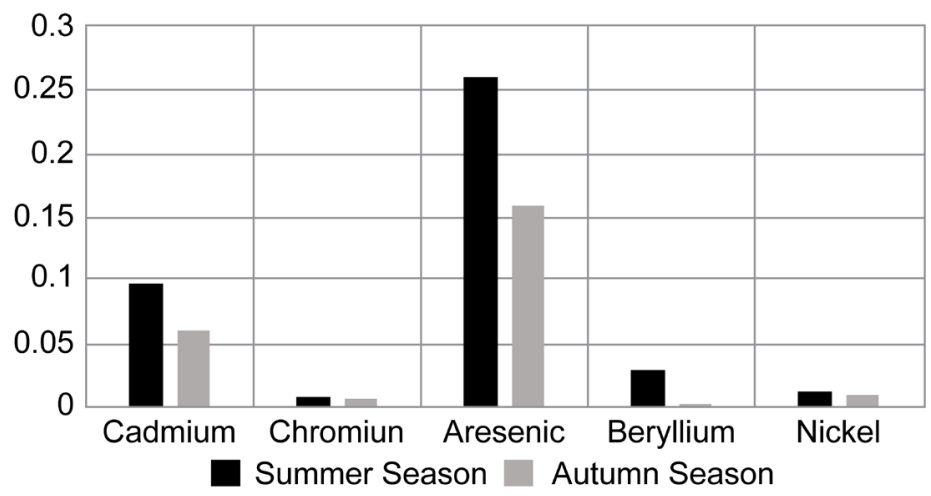

Figure 2. Seasonal average concentrations of trace elements in $\mathrm{PM}_{10}$ at the monitoring site in Arafat area from June to November 2014. 




Figure 3. Correlation plot of trace elements in $\mathrm{PM}_{10}$ at the monitoring site in Arafat area from June to November 2014.

\subsection{Meteorological Measurements}

The highest average wind speed of $4 \mathrm{~m} / \mathrm{s}$ (gentle breeze) was noted in June, at which time the average daily maximum wind speed was $8 \mathrm{~m} / \mathrm{s}$ (fresh breeze). The lowest average wind speed of $3 \mathrm{~m} / \mathrm{s}$ (light breeze) was noted in October, Figure 4 . All other meteorological parameters measurements were in the seasonal normal range.

\subsection{Risk Assessment}

The ECRs for the Arafat area were $1.08 \times 10^{-4}, 7.21 \times 10^{-4}, 4.0 \times 10^{-6}, 4.6 \times 10^{-6}$, and $2.4 \times 10^{-6}$ for $\mathrm{Cd}, \mathrm{Cr}, \mathrm{As}, \mathrm{Be}$, and Ni respectively, Table 5; these values exceeded the level of acceptable inhalation risk $\left(1.0 \times 10^{-6}\right)$ for each element set by the USEPA [8].

\section{Conclusions}

Arsenic had the highest concentration among all the five carcinogenic trace elements studied. The ECRs for the Arafat area for each of the five trace elements exceeded the level of acceptable inhalation risk $\left(1.0 \times 10^{-6}\right)$ for each element set by the USEPA. Although it is not possible to accurately determine the population exposure to ambient air pollution as there is limited knowledge regarding time-activity patterns, pollutant concentrations are considered to indicate the exposure level.

To the best of our knowledge, this is the first study to assess airborne trace element concentrations and their correlation with cancer risk in Makkah. Further studies are required to monitor and assess additional trace elements and their carcinogenic effect as well as the effects of long- and short-term exposure and the contribution of different air pollution sources, particularly road traffic, which is the main source of several air pollutants in urban areas. Moreover, larger prospective studies are warranted to explore the health effects of long-term exposure to ambient air trace elements. Further monitoring plans should be adopted in Makkah for preventing long-term exposure at different monitoring locations, including pilgrimage sites, roadside, and urban sites. 


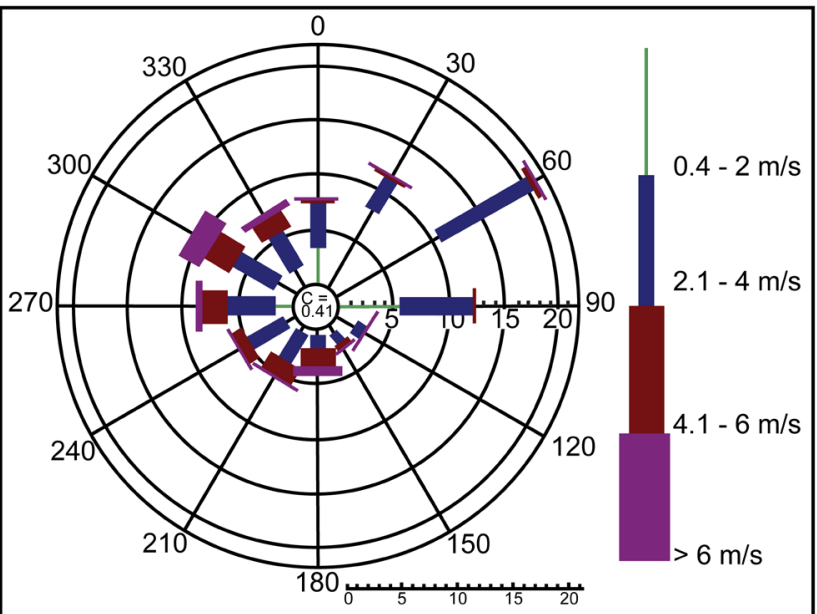

Wind Rose: June 1, 2014 to December 31, 2014 (Arafat Site)



Wind Rose: Summer Season, 2014

Figure 4. Wind roses for the Arafat area during the 2014 fall and summer seasons showing wind direction and the percentage of time that winds blew from a direction at certain speed ranges. Wind speeds shown in the plots are in $\mathrm{m} / \mathrm{s}$.

Table 5. Assessment of cancer risk in the exposed population based on trace element concentration in inhalable ambient air from June to November 2014.

\begin{tabular}{cccc}
\hline $\begin{array}{c}\text { Trace } \\
\text { Elements }\end{array}$ & Ambient Exposure $\left(\mu \mathrm{g} / \mathrm{m}^{3}\right)$ & Inhalation Unit Risk $\left(\mu \mathrm{g} / \mathrm{m}^{3}\right)$ & ECR $\left(\mu \mathrm{g} / \mathrm{m}^{3}\right)$ \\
\hline $\mathrm{Cd}$ & 0.098 & $1.8 \times 10^{-3}$ & $1.08 \times 10^{-4}$ \\
$\mathrm{Cr}$ & 0.008 & $1.2 \times 10^{-2}$ & $7.21 \times 10^{-4}$ \\
$\mathrm{As}$ & 0.016 & $1.6 \times 10^{-3}$ & $4.4 \times 10^{-6}$ \\
$\mathrm{Be}$ & 0.03 & $4.0 \times 10^{-4}$ & $4.6 \times 10^{-6}$ \\
$\mathrm{Ni}$ & 0.012 & $2.0 \times 10^{-2}$ & $2.4 \times 10^{-6}$ \\
\hline
\end{tabular}

Excess cancer risk.

\section{Acknowledgements}

This study was funded by King Abdulaziz City for Science and Technology (KACST) under the National Science, Technology and Innovation Plan (NSTIP), KSA.

\section{Authors' Contributions}

All authors equally contributed in the article. All authors read and approved the final manuscript.

\section{Conflict of Interests}

The authors declare that they have no competing interests regarding the publication of this manuscript.

\section{Compliance with Ethical Standards}

The study protocol was approved by Ethics Review Board for Human Studies at Faculty of Medicine, Umm Al-Qura University and conformed to the ethical guidelines of the 1975 Helsinki declaration. 


\section{References}

[1] Allen, H.E. (2002) Bioavailability of Metals in Terrestrial Ecosystems: Importance of Partitioning for Bioavailability to Invertebrates, Microbes and Plants. Metals and Environment Series, SETAC Press, USA.

[2] Hieum, N.T. and Lee, B.K. (2010) Characteristic of Particulate Matter and Metals in the Ambient Air from a Residential Area in the Largest Industrial City in Korea. Atmospheric Research, 98, 526-537. https://doi.org/10.1016/j.atmosres.2010.08.019

[3] Chen, L.C. and Lippmann, M. (2009) Effects of Metals within Ambient Air Particulate Matter on Human Health. Inhalation Toxicology, 21, 1-31. https://doi.org/10.1080/08958370802105405

[4] Multa, A., Byeong, K.L., Park, G. and Yu, B.G. (2012) Long Term Concentrations of Airborne Cadmium in Metropolitan Cities in Korea and Potential Health Risks. Atmospheric Environment, 47, 164-173. https://doi.org/10.1016/j.atmosenv.2011.11.019

[5] Van, B.L. and Casee, F.R. (2009) Toxicity of Ambient Air PM 10 : A Critical Review of Potentially Causative PM Properties and Mechanism Associated with Health Effects, National Institute of Public Health and Environment, Bilthoven.

[6] Vassilakos, C.H., Veros, D., Michopoulos, J., Maggos, T. and O’Connor, C.M. (2010) Estimation of Selected Heavy Metals and Arsenic in PM10 Aerosols in the Ambient Air of Greater Athens Area. Journal of Hazardous Materials, 140, 389-398. https://doi.org/10.1016/j.jhazmat.2006.11.002

[7] Wojas, B. and Almquist, C. (2007) Mass Concentrations and Metals Speciation of $\mathrm{PM}_{2.5}, \mathrm{PM}_{10}$ and Total Suspended Solids in Oxford, Ohio and Comparison with Those from Metropolitan Sites in the Greater Cincinnati Region. Atmospheric Environment, 41, 9064-9078. https://doi.org/10.1016/j.atmosenv.2007.08.010

[8] United States Environmental Protection Agency (1999) Integrated Risk Information System on Trivalent Chromium. National Center for Environmental Assessment, Office of Research and Development, Washington DC.

[9] Agency for Toxic Substance and Disease Registry (1998) Toxicological Profile for Arsenic. Public Health Service. US Department of Health and Human Health Services, Atlanta.

[10] Centers for Disease Control and Prevention (2005) Third National Report on Human Exposure to Environmental Chemicals. Department of Health and Human Services, Atlanta.

[11] Amodio, M., Bruno, P. and Caselli, M. (2009) Chemical Characterization of Fine Particulate Matter during Peak PM10 Episode (South Italy). Atmospheric Research, 90, 313-325. https://doi.org/10.1016/j.atmosres.2008.07.003

[12] Fang, G.C., Huang, Y.L. and Huang, J.H. (2010) Study of Atmospheric Metallic Elements in Asia. Journal of Hazardous Materials, 180, 115-121.

https://doi.org/10.1016/j.jhazmat.2010.03.120

[13] Lee, B.K. and Park, G.H. (2010) Characteristics of Heavy Metals in Airborne Particulate Matter on Misty and Clear Days. Journal of Hazardous Materials, 184, 406416. https://doi.org/10.1016/j.jhazmat.2010.08.050

[14] Habeebullah, T.M. (2013) Risk Assessment of Poly Cyclic Aromatic Hydrocarbons in the Holy City of Makkah, Saudi Arabia. International Journal of Environmental Science and Development, 4, 139-142. https://doi.org/10.7763/IJESD.2013.V4.322

[15] Habeebullah, T.M. (2012) Health Impacts of PM10 Using AirQ2.2.3 Model in Makkah. Journal of Basic \& Applied Sciences, 9, 259-268. 
[16] Habeebullah, T.M. (2014) Modelling Particulate Matter PM10 in Makkah, Saudi Arabia-A View Point of Health Impact. Journal of Clean Energy Technologies, 2, 196-200. https://doi.org/10.7763/JOCET.2014.V2.122

[17] Munir, S., Habeebullah, T.M., Gabr, S.S., Morssey, E., Mohamed, A.M.F. and ElSoud, W.A. (2016) Application of ADMS-Urban in the Holy City of Makkah-Modelling Particulate Matter (Part 2). International Journal of Agricultural and Environmental Research, 2, 24-31.

[18] Habeebullah, T.M.A. (2016) Chemical Composition of Particulate Matters in Makkah-Focusing on Cations, Anions and Heavy Metals. Aerosol and Air Quality Research, 16, 336-347. https://doi.org/10.4209/aaqr.2015.08.0486

[19] Saudi Ministry of Health (2013) Health Statistics Book on Pilgrims. General Directorate of Statistics and Information. Ministry of Health. Kingdom of Saudi Arabia. www.moh.gov.sa

[20] US Quality Assurance Handbook for Air Pollution Measurement Systems (2013) Volume IV: Meteorological Measurements. US Environmental Protection Agency Office of Air Quality Planning and Standards Air Quality Assessment Division, Research Triangle Park.

[21] Framework for Metals Risk Assessment (2007) Office of the Science Advisor Risk Assessment Forum US Environmental Protection Agency. Washington DC.

[22] Habeebullah, T.M., Seroji, A., Morsy, E., Munir, S., Mohamed, A. and Abu, S.W. (2016) The Effect of Street Dust on Urban Environment. International Journal of Environmental and Ecological Engineering, 3, 4246-4251.

[23] Munir, S., Habeebullah, T., Seroji, A., Morsy, E., Mohammed, A., Abu Saud, W., et al. (2013) Modelling Particulate Matter Concentrations in Makkah, Applying a Statistical Modeling Approach. Aerosol and Air Quality Research, 13, 901-910.

Submit or recommend next manuscript to SCIRP and we will provide best service for you:

Accepting pre-submission inquiries through Email, Facebook, LinkedIn, Twitter, etc. A wide selection of journals (inclusive of 9 subjects, more than 200 journals)

Providing 24-hour high-quality service

User-friendly online submission system

Fair and swift peer-review system

Efficient typesetting and proofreading procedure

Display of the result of downloads and visits, as well as the number of cited articles

Maximum dissemination of your research work

Submit your manuscript at: http://papersubmission.scirp.org/

Or contact jep@scirp.org 